\title{
Intra-articular injection of tranexamic acid via a drain plus drain-clamping to reduce blood loss in cementless total knee arthroplasty
}

Hirotaka Mutsuzaki ${ }^{{ }^{*}}$ and Kotaro $\mid k e d a^{2}$

\begin{abstract}
Background: Patients undergoing cementless total knee arthroplasty (TKA) sometimes suffer large blood loss. In a retrospective study, we explored whether postoperative intra-articular retrograde injection of tranexamic acid (TA) and leaving a drain clamp in place for $1 \mathrm{~h}$ reduced blood loss.

Patients and methods: Patients $(n=140)$ treated with unilateral primary cementless TKA (posterior cruciate ligament retained) were divided into two groups: those who had an intra-articular injection of TA (1000 mg) and drain clamping for $1 \mathrm{~h}$ postoperatively (study group, $n=70$ ) and those who were not given TA and did not undergo clamping of their drains (control group, $n=70$ ). Postoperative total blood loss, volume of drainage, hemoglobin level, transfusion amounts and rates, D-dimer level at postoperative day (POD) 7, and complications were recorded.

Results: Total blood loss, total drainage, mean transfusion volume, and transfusion rates were lower in the study group than in controls $(P<0.001)$. Hemoglobin levels on PODs 1 and 14 were similar in the groups, but on POD 7 the hemoglobin level was higher in the study group than in controls $(P<0.001)$. D-dimer level on POD 7 was lower in the study group than in controls $(P<0.05)$. There were no complications in either group.

Conclusions: Immediately postoperative intra-articular retrograde injection of TA and $1 \mathrm{~h}$ of drain-clamping effectively reduced blood loss and blood transfusion after cementless TKA. We believe that this method is simple, easy, and suitable for these patients.
\end{abstract}

Keywords: Intra-articular injection, Tranexamic acid, Drain-clamping, Blood loss, Cementless, Total knee arthroplasty

\section{Introduction}

Blood loss is unavoidable after total knee arthroplasty (TKA) [1-3]. Controlling perioperative blood loss is especially a major concern with cementless TKA [4-7]. Two recent meta-analyses were performed to evaluate the use of intravenous tranexamic acid (TA) to reduce blood loss and the need for transfusion after total hip arthroplasty and TKA $[8,9]$. Based on the results of clinical trials considered suitable for evaluation, it was concluded that TA appears to be a cost-effective, safe method to reduce blood loss, and thus the need for

\footnotetext{
* Correspondence: mutsuzaki@ipu.ac.jp

${ }^{1}$ Department of Orthopaedic Surgery, Ibaraki Prefectural University of Health Sciences, 4669-2 Ami, Ami-machi, Inashiki-gun, Ibaraki 300-0394, Japan Full list of author information is available at the end of the article
}

allogenic blood transfusion, without increasing thromboembolic complications.

Tranexamic acid inhibits tissue fibrinolysis for up to $17 \mathrm{~h}$ and consequently stabilizes the possibility of clots entering the extravascular space and accumulating in tissues [10]. It is generally accepted, however, that only a small percentage of intravenously injected TA reaches the target location. Thus, a more efficient method (i.e., intra-articular injection) to deliver TA is desirable $[11,12]$. Another method used to reduce blood loss is drain-clamping [13-18].

One strategy for reducing blood loss after cementless TKA includes drain-clamping combined with intraarticular administration of TA plus carbazochrome sodium sulfonate and fibrin glue [19]. We modified that method to make it simpler, easy to use, suitable for these

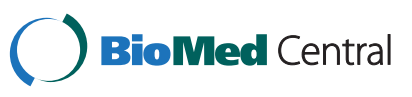


patients, and understandable for clinicians. We administered TA intra-articularly after cementless TKA, injecting it retrogradely through the drain at the end of the operation and then clamped the drain for $1 \mathrm{~h}$.

The effect of this treatment on reducing postoperative bleeding after cementless TKA has not been reported. Our hypothesis was that intra-articular administration of TA via the drain and then clamping the drain for an hour would reduce postoperative bleeding after cementless TKA.

\section{Patients and methods}

This study, conducted from June 2007 through March 2012, was nonrandomized and retrospective. It included 140 knees undergoing unilateral primary cementless TKA (retaining the posterior cruciate ligament). The ethics committee of Ichihara Hospital reviewed and approved the study (the reference number for the ethics approval: 1202, and the trial registration number: 1202). Informed consent was obtained from each patient. Exclusion criteria were known allergy to TA, cemented TKA, bilateral TKAs, and posterior stabilized TKA. After these exclusions, 140 patients remained. They were divided into two groups. The study group underwent retrograde intra-articular injection of TA via the drain at the end of the operation followed by clamping the drain for $1 \mathrm{~h}(\mathrm{n}=70)$ (from January 2010 through March 2012). The control group did not undergo this treatment ( $\mathrm{n}=70$ ) (from June 2007 through October 2009). The preoperative characteristics, including age, sex, any knee disease, height, weight, preoperative femorotibial angle, range of motion of the knee, and hemoglobin levels 1 day before surgery were comparable in the two groups (Table 1). The backgrounds of the patients in the groups were not significantly different. All surgery was performed or supervised by a single surgeon (K.I.).

All patients were given general anesthesia. The patella was not replaced, the posterior curuciate ligament was retained, and all components were fixed without cement in all 140 patients. Surgery was performed under tourniquet control. After a midline skin incision was made, a medial parapatellar approach was used. An intramedullary alignment rod was used for femoral cutting and an extramedullary guide system for tibial cutting. The femoral canal for intramedullary guidance was routinely plugged with bone. We did not use red cell salvaging device.

The implants used in all patients were the Scorpio NRG CR HA (Stryker Howmedica Osteonics, Allendale, NJ, USA) or the NexGen CR (Zimmer, Warsaw, IN, USA). With the NexGen CR type, the femoral component was HA-TCP CR Femoral or CR-flex Porus Femoral. The tibial component was NexGen CR HA-TCP Tibia Peg, NexGen CR HA-TCP Stem Tibia, or NexGen Trabecular Metal Monoblock Tibia. Scorpio NRG CR HA was used in 19 knees in the study group and 37 knees in the control group. NexGen CR type was used in 51 knees in the study group and 33 knees in the control group. NexGen CR HA-TCP Tibia Peg was used in 3 knees in the study group and 15 knees in the control group. NexGen CR HA-TCP Stem Tibia was used in 13 knees in the study group and 18 knees in the control group. NexGen Trabecular Metal Monoblock Tibia was used in 35 knees in the study group and 0 knees in the control group. HA-TCP CR Femoral was used in 21 knees in the study group and 33 knees in the control group. CR-flex Porus Femoral was used in 30 knees in the study group and 0 knees in the control group. The implant types used were not significantly different in the two groups using the Mann-Whitney $U$-test $(P=0.591)$.

Because of the reduced blood loss, the tourniquet was not released until skin closure and application of a compressive dressing [20]. Intraoperative blood loss was negligible in all patients because the tourniquet was not deflated until wound closure. We used an intra-articular drain connected to a vacuum bag (J-VAC suction reservoir $450 \mathrm{ml}$; Johnson \& Johnson K.K., Tokyo, Japan). In the study group, intra-articular administration of TA was injected via the drain retrogradely before releasing of the tourniquet, and the drain was then clamped for $1 \mathrm{~h}$. We

Table 1 Patient profiles

\begin{tabular}{|c|c|c|c|}
\hline & Study group $(n=70)$ & Control group $(n=70)$ & $P$ value \\
\hline Age (year) & $72.0 \pm 7.3$ & $74.1 \pm 7.1$ & NS \\
\hline Sex (male/female) & $16 / 54$ & $17 / 53$ & NS \\
\hline Disease (OA/RA) & $68 / 2$ & $69 / 1$ & NS \\
\hline Height (cm) & $150.7 \pm 8.0$ & $150.9 \pm 7.8$ & NS \\
\hline Body weight (kg) & $62.3 \pm 11.0$ & $63.1 \pm 9.5$ & NS \\
\hline Preoperative FTA $\left(^{\circ}\right)$ & $184.8 \pm 6.5$ & $184.7 \pm 8.0$ & NS \\
\hline Preoperative ROM $\left({ }^{\circ}\right)$ & $108.2 \pm 25.4$ & $114.3 \pm 18.2$ & NS \\
\hline Preoperative $\mathrm{Hb}(\mathrm{g} / \mathrm{dl})$ & $12.6 \pm 1.4$ & $12.7 \pm 1.4$ & NS \\
\hline
\end{tabular}

$O A$ osteoarthritis, $R A$ rheumatoid arthritis, FTA femorotibial angle, $R O M$ range of motion, $\mathrm{Hb}$ hemoglobin.

Results are the mean \pm SD. 
based this interval on previous data indicating that $1 \mathrm{~h}$ of clamping was effective [17]. Also, $1 \mathrm{~h}$ of clamping is simple and understandable for clinicians.

The amount of TA to be injected was chosen to be 1 ampoule (10\% Transamin, $10 \mathrm{ml}, 1000 \mathrm{mg}$; DaiichiSankyo, Tokyo, Japan). This dose was found acceptable in previous studies [4-8]. Also, a single ampoule is a simple quantity and understandable for clinicians. In both groups in our study, the drains were removed $48 \mathrm{~h}$ after the operation.

Following surgery, all patients underwent intravenous prophylactic antibiotic therapy consisting of $1 \mathrm{~g}$ cefazolin every $12 \mathrm{~h}$ for 3 days. Standard thromboprophylaxis was also prescribed for all patients after surgery. It was administered subcutaneously and included $1.5-2.5 \mathrm{mg}$ fondaparinux sodium (Arixtra ${ }^{\circledR}$ Injection; Glaxo-Smith-Kline, Brentford, Middlesex, UK) starting $24 \mathrm{~h}$ after surgery and continuing every $24 \mathrm{~h}$ for 10 days. A foot pump (Novamedix A-V Impulse System; Kobayashi Medical, Osaka, Japan) and antiembolic stockings (Ansilk ${ }^{\circledR}$; ALCARE, Tokyo, Japan) were used for thromboembolic prophylaxis $[21,22]$.

Sutures were removed from all patients 2 weeks after surgery. As part of the postoperative care for both groups, continuous passive movement was started on postoperative day (POD) 3, and standing and full weight-bearing walking were allowed 1 week after the operation.

If possible, autologous blood was collected on preoperative day 4 or earlier. Indications for preoperative autologous blood donations were based on the Standards for Preoperative Autologous Blood Donations (2007) developed by the Japanese Society of Autologous Blood Transfusions. A blood hemoglobin level of $\geq 11.0 \mathrm{~g} / \mathrm{dl}$ or a hematocrit of $\geq 33 \%$ was required. No age limit was established. Iron injection was administered at a dose of $80 \mathrm{mg}$ at blood collection. When collection of $\geq 800 \mathrm{ml}$ of blood took $\geq 1$ week, 24,000 units of recombinant human erythropoietin $\left(\mathrm{ESPO}^{\circledR}\right.$, epoetinum alfa; Kyowa Kirin, Tokyo, Japan) was administered subcutaneously. On POD 1, all the autologous blood was transfused to each patient.

We used the principle of transfusion based on the criteria and guidelines for perioperative transfusion suggested by the National Institutes of Health Consensus Conference, which states that the decision to transfuse blood depends on clinical assessment aided by laboratory data indicating that the patient has symptoms and signs associated with acute anemia [23]. Therefore, our indication for blood transfusion was set at a hemoglobin concentration of $8.5 \mathrm{~g} / \mathrm{dl}$ or a postoperative hemoglobin level of $8.5-9.0 \mathrm{~g} / \mathrm{dl}$ with clinical evidence of acute anemia [24]. It may be adjusted according to the patient's cardiovascular status.
Bleeding-related outcome measures included drainedblood loss, total postoperative blood loss, need for autogenic or allogenic blood transfusions, and the transfusion rate. Hemoglobin levels were measured on PODs 1, 7, and 14. A formula proposed by Nadler et al. [25] and Sehat et al. [26] was used to calculate the total postoperative blood loss. It was based on the maximum postoperative decrease in hemoglobin level adjusted for the weight and height of the patient. The loss of $\mathrm{Hb}$ was then estimated according to the following formula:

$$
\begin{aligned}
\text { Blood volume }(\mathrm{l})= & \text { height }(\mathrm{m})^{3} \times 0.356 \\
& + \text { body weight }(\mathrm{kg}) \times 0.033 \\
& +0.183(\text { woman }) \\
= & \text { height }(\mathrm{m})^{3} \times 0.367 \\
& + \text { body weight }(\mathrm{kg}) \times 0.032 \\
& +0.604(\operatorname{man}) \mathrm{Hb} \text { loss }(\mathrm{g}) \\
= & \text { Blood volumex10x }\left(\mathrm{Hb}_{\mathrm{i}}-\mathrm{Hb}_{\mathrm{fin}}\right) \\
& +\mathrm{Hb}_{\mathrm{t}} \operatorname{Total}_{\mathrm{blood}} \operatorname{loss}(\mathrm{ml}) \\
= & \text { Hb }_{\text {loss }} / \mathrm{Hb}_{\mathrm{i}} \mathrm{x} 100
\end{aligned}
$$

where $\mathrm{Hb}_{\text {loss }}(\mathrm{g})$ was the amount of $\mathrm{Hb}$ lost, $\mathrm{Hb}_{\mathrm{i}}(\mathrm{g} / \mathrm{dl})$ was the $\mathrm{Hb}$ concentration before surgery, $\mathrm{Hb}_{\text {fin }}(\mathrm{g} / \mathrm{dl})$ was the $\mathrm{Hb}$ concentration on $\mathrm{POD} 7$, and $\mathrm{Hb}_{\mathrm{t}}(\mathrm{g})$ was the total amount of allogeneic and autologous $\mathrm{Hb}$ transfused.

We recorded the operating time, and the D-dimer level was assayed 7 days after the surgery. We also monitored the wound condition (skin necrosis, hematoma, infection) and the possibility of deep venous thrombosis (DVT) and/or pulmonary embolism (PE) for 4 weeks after the operation.

\section{Statistical analyses}

Student's $t$-test was used to analyze parametric data, and the Mann-Whitney $U$-test was used for nonparametric data. $P \leq 0.05$ was considered a significant difference.

\section{Results}

The results are summarized in Table 2. The total blood loss was less in the study group than in the control group $(633.8 \pm 317.2$ vs. $1276.0 \pm 327.1 \mathrm{ml}, P<0.001)$. The total drainage during $0-48 \mathrm{~h}$ postoperatively was less in the study group than in the control group $(271.1 \pm 201.8$ vs. $506.4 \pm 256.8 \mathrm{ml}, P<0.001)$. There was a greater reduction in both autogenic and allogeneic transfusion rates in the study group than in the control group $(10.0 \%$ vs. $65.7 \%, P<0.001$ and $10.0 \%$ vs. $31.4 \%, P<0.001$, respectively). The mean amounts of transfusion per patient for both autogenic and allogeneic transfusions were less in the study group than in the control group (40.0 \pm 120.9 vs. $264.1 \pm 195.5 \mathrm{ml}, P<0.001$ and $0.2 \pm 0.7$ vs. $1.1 \pm 1.7$ units, $P<0.001$, respectively). The hemoglobin level on POD 1 was similar in the two groups, but on POD 7 it 
Table 2 Postoperative data for all patients

\begin{tabular}{|c|c|c|c|}
\hline Parameter & Study group $(n=70)$ & Control group $(n=70)$ & $P$ value \\
\hline Operative time (min) & $68.8 \pm 14.2$ & $82.7 \pm 16.8$ & $<0.001$ \\
\hline \multicolumn{4}{|l|}{ Postoperative $\mathrm{Hb}(\mathrm{g} / \mathrm{dl})$} \\
\hline POD 1 & $11.3 \pm 1.2$ & $11.1 \pm 1.3$ & NS \\
\hline POD 7 & $10.7 \pm 1.3$ & $10.1 \pm 1.1$ & $<0.001$ \\
\hline POD 14 & $10.9 \pm 1.1$ & $10.7 \pm 1.0$ & NS \\
\hline \multicolumn{4}{|l|}{ Blood loss (ml) } \\
\hline Drained & $271.1 \pm 201.8$ & $506.4 \pm 256.8$ & $<0.001$ \\
\hline Total & $633.8 \pm 317.2$ & $1276.0 \pm 327.1$ & $<0.001$ \\
\hline \multicolumn{4}{|l|}{ Transfusions } \\
\hline Autologous (ml) & $40.0 \pm 120.9$ & $264.1 \pm 195.5$ & $<0.001$ \\
\hline Allogeneic (units) & $0.2 \pm 0.7$ & $1.1 \pm 1.7$ & $<0.001$ \\
\hline \multicolumn{4}{|l|}{ Transfusion rate (\%) } \\
\hline Autologous & 10.0 & 65.7 & $<0.001$ \\
\hline Allogeneic & 10.0 & 31.4 & $<0.001$ \\
\hline D-dimer level 7 days after surgery $(\mu \mathrm{g} / \mathrm{ml})$ & $6.8 \pm 2.4$ & $7.7 \pm 3.8$ & 0.042 \\
\hline
\end{tabular}

Results are the mean \pm SD.

was greater in the study group than in the control group $(10.7 \pm 1.3 \mathrm{~g} / \mathrm{dl}$ vs. $10.1 \pm 1.1 \mathrm{~g} / \mathrm{dl}, P<0.001)$.

The operating time was shorter in the study group than in the control group $(68.8 \pm 14.2$ vs. $82.7 \pm 16.8 \mathrm{~min}, P<$ $0.001)$. There were no significant differences in the two groups regarding the implant types. The D-dimer level, measured on POD 7, was lower in the study group than in the control group $(6.8 \pm 2.4$ vs. $7.7 \pm 3.8 \mu \mathrm{g} / \mathrm{ml}, P=$ 0.042). Finally, symptomatic deep vein thrombosis, pulmonary embolism, and wound trouble including necrosis, infection, and hematoma were not observed in either group.

\section{Discussion}

The most important finding of the present study was that intra-articular retrograde injection of TA via the drain at the end of the operation and then clamping the drain for $1 \mathrm{~h}$ effectively reduced postoperative blood loss and thus the need for blood transfusion after cementless TKA. This method is simple, easy to perform, suitable for these patients, and understandable for clinicians. Although, the total blood loss in the controls was greater than that of previous studies $[4,5]$, the use of fondaparinux sodium for thromboprophylaxis can be influenced. The effect of TA and drain-clamping in patients undergoing cementless TKA was certainly clarified, similar to previous studies [11-18].

The fibrinolytic system is activated transiently after any surgery [27]. Tranexamic acid is a synthetic amino acid that inhibits fibrinolysis by reversibly blockading lysine-binding sites on plasminogen molecules, thereby inhibiting its activation. This prevents plasmin from binding with fibrinogen and fibrin structures after clot formation [28]. Because of its antifibrinolytic effects, the risk of increasing venous thromboembolism when using TA is a cause for concern [29,30]. Tranexamic acid does not influence fibrinolytic activity in vein walls, however [30]. Therefore, neither our study nor previous studies observed a greater incidence of venous thrombosis in patients treated with TA [31-33]. Also, the D-dimer level in the study group was lower than that in the control group. The incidence of subcutaneous and intra-joint hematomas was reduced in the study group compared to the control group because of the small amount of bleeding after TKA.

One of the main problems after TKA is the need for blood transfusion. Although the incidence is low, serious complications involving allogeneic blood transfusions (e.g., viral infections, graft-versus-host disease) have been reported [34]. Because the need for blood transfusion was reduced using our method, transfusion-associated complications were reduced. Intra-articular TA application after TKA has recently been introduced and has proved to reduce significantly postoperative blood loss and knee swelling $[11,12]$. It can also reduce the dose of TA needed to reduce postoperative blood loss [12]. Disadvantages of intravenous TA are prolonged high systemic drug levels from multiple injections or continuous infusion, leading to drug-induced systemic thromboembolic events $[8,9]$. Further investigations using smaller amounts of TA than were given in this study may be required.

In our study, the operating time was longer for the control group than for the study group. This finding may have been influenced by our use of different 
implant types. The NexGen Trabecular Metal Monoblock Tibia implant had a trend to be used more often in the study group than in the control group. The tibial base plate of this device originally was fixed with a polyethylene insert. Also, screws were not used for fixation of the tibia to the tibial base plate. Other tibial base plates have screws that fix the tibia and separate the polyethylene insert. Increased time may be required for operations in which screws are used for fixation of the tibia to the base plate and for inserting polyethylene. Although it is unclear whether there was greater blood loss in the control group, a longer operating time does not imply a greater chance of postoperative bleeding [35]. Further investigations using the same implant may be required.

The study has limitations. First, it was retrospective. Although there were no differences in patient characteristics in the two groups, selection bias was not completely excluded. Second, more studies (randomized controlled trials) are needed to determine dosage and administration. Also, investigations using thromboembolism screening tests such as ultrasonography may be required.

Intra-articular injection of TA retrogradely via the drain at the end of the operation and clamping the drain for $1 \mathrm{~h}$ effectively reduced postoperative blood loss and the need for blood transfusion after cementless TKA. We believe that our modifications of this technique have made it a simple, easy-to-use method that is suitable for these patients and understandable for clinicians.

\section{Competing interests}

The authors declare that they have no competing interests.

\section{Authors' contributions}

$\mathrm{HM}$ and $\mathrm{KI}$ conceived of the study and participated in its design and coordination. H.M. participated in the sequence alignment and drafted the manuscript. All authors have read and approved the final manuscript.

\section{Acknowledgments}

The authors are grateful to Dr. Tomonori Kinugasa for technical assistance.

\section{Author details}

'Department of Orthopaedic Surgery, Ibaraki Prefectural University of Health Sciences, 4669-2 Ami, Ami-machi, Inashiki-gun, Ibaraki 300-0394, Japan. ${ }^{2}$ Department of Orthopaedic Surgery, Ichihara Hospital, 3681 Ozone, Tsukuba, Ibaraki 300-3295, Japan.

Received: 7 May 2012 Accepted: 27 September 2012

Published: 29 September 2012

\section{References}

1. Brecher ME, Monk T, Goodnough LT: A standardized method for calculating blood loss. Transfusion 1997, 37:1070-1074.

2. Callaghan JJ, O'Rourke MR, Liu SS: Blood management: issues and options. J Arthroplasty 2005, 20:51-54.

3. Mylod AG Jr, France MP, Muser DE, et al: Perioperative blood loss associated with total knee arthroplasty: a comparison of procedures performed with and without cementing. J Bone Joint Surg Am 1990, 72:1010-1012
4. Ishii $Y$, Matsuda Y: Perioperative blood loss in cementless or hybrid total knee arthroplasty without patellar resurfacing: a prospective, randomized study. J Arthroplasty 2005, 20:972-976.

5. Ishii Y, Matsuda Y: Effect of the timing of tourniquet release on perioperative blood loss associated with cementless total knee arthroplasty: a prospective randomized study. J Arthroplasty 2005 20:977-983

6. Akizuki S, Takizawa T, Horiuchi H: Fixation of a hydroxyapatite-tricalcium phosphate-coated cementless knee prosthesis. Clinical and radiographic evaluation seven years after surgery. J Bone Joint Surg Br 2003, 85:1123-1127.

7. Saito $S$, Tokuhashi $Y$, Ishii $T$, et al: Bilateral fatigue fracture of the femoral components in a cruciate-retaining cementless total knee prosthesis. Orthopedics 2011, 34:e688-e691.

8. Ho KM, Ismail H: Use of intravenous tranexamic acid to reduce allogenic blood transfusion in total hip and knee arthroplasty: a meta-analysis. Anaesth Intensive Care 2003, 31:529-537.

9. Cid J, Lozano M: Tranexamic acid reduces allogenic red cell transfusions in patients undergoing total knee arthroplasty: results of a meta-analysis of randomized controlled trials. Transfusion 2005, 45:1302-1307.

10. Mannucci PM: Hemostatic drugs. N Engl J Med 1998, 339:245-253.

11. Ishida K, Tsumura N, Kitagawa A, et al: Intra-articular injection of tranexamic acid reduces not only blood loss but also knee joint swelling after total knee arthroplasty. Int Orthop 2011, 35:1639-1645.

12. Sa-Ngasoongsong P, Channoom T, Kawinwonggowit V, et al: Postoperative blood loss reduction in computer-assisted surgery total knee replacement by low dose intra-articular tranexamic acid injection together with 2-h clamp drain: a prospective triple-blinded randomized controlled trial. Orthop Rev (Pavia) 2011, 3:e12.

13. Ryu J, Sakamoto A, Honda T, et al: The postoperative drain-clamping method for hemostasis in total knee arthroplasty. Reducing postoperative bleeding in total knee arthroplasty. Bull Hosp Jt Dis 1997, 56:251-254

14. Yamada K, Imaizumi T, Uemura M, et al: Comparison between 1-h and 24-h drain clamping using diluted epinephrine solution after total knee arthroplasty. J Arthroplasty 2001, 16:458-462.

15. Kiely N, Hockings M, Gambhir A: Does temporary clamping of drains following knee arthroplasty reduce blood loss? A randomised controlled trial. Knee 2001, 8:325-327.

16. Tsumara N, Yoshiya S, Chin T, et al: A prospective comparison of clamping the drain or postoperative salvage of blood in reducing blood loss after total knee arthroplasty. J Bone Joint Surg Br 2006, 88:49-53.

17. Roy N, Smith M, Anwar M, et al: Delayed release of drain in total knee replacement reduces blood loss. A prospective randomised study. Acta Orthop Belg 2006, 72:34-38.

18. Stucinskas J, Tarasevicius S, Cebatorius A, et al: Conventional drainage versus four hour clamping drainage after total knee arthroplasty in severe osteoarthritis: a prospective, randomised trial. Int Orthop 2009, 33:1275-1278.

19. Akizuki S, Yasukawa Y, Takizawa T: A new method of hemostasis for cementless total knee arthroplasty. Bull Hosp Jt Dis 1997, 56:222-224.

20. Rama KR, Apsingi S, Poovali $S$, et al: Timing of tourniquet release in knee arthroplasty. Meta-analysis of randomized, controlled trials. J Bone Joint Surg Am 2007, 89:699-705.

21. Morris RJ, Woodcock JP: Evidence-based compression: prevention of stasis and deep vein thrombosis. Ann Surg 2004, 239:162-171.

22. Stannard JP, Harris RM, Bucknell AL, et al: Prophylaxis of deep venous thrombosis after total hip arthroplasty by using intermittent compression of the plantar venous plexus. Am J Orthop (Belle Mead NJ) 1996, 25:127-134.

23. National Institutes of Health Consensus Conference: Perioperative red blood cell transfusion. JAMA 1988, 260:2700-2703.

24. Aderinto J, Brenkel IJ: Pre-operative predictors of the requirement for blood transfusion following total hip replacement. J Bone Joint Surg Br 2004, 86:970-973.

25. Nadler SB, Hidalgo JU, Blouch T: Prediction of blood volume in normal human adults. Surgery 1962, 51:224-232.

26. Sehat KR, Evans RL, Newman JH: Hidden blood loss following hip and knee arthroplasty. Correct management of blood loss should take hidden loss into account. J Bone Joint Surg Br 2004, 86:561-565. 
27. Risberg B: The response of the fibrinolytic system in trauma. Acta Chir Scand Suppl 1985, 522:245-271.

28. Dunn CJ, Goa KL: Tranexamic acid. A review of its use in surgery and other indications. Drugs 1999, 57:1005-1032.

29. Arnljots B, Wieslander JB, Dougan P, et al: Importance of fibrinolysis in limiting thrombus formation following severe microarterial trauma: an experimental study in the rabbit. Microsurgery 1991, 12:332-339.

30. Astedt B, Liedholm P, Wingerup L: The effect of tranexamic acid on the fibrinolytic activity of vein walls. Ann Chir Gynaecol 1978, 67:203-205.

31. Benoni $\mathrm{G}$, Fredin H: Fibrinolytic inhibition with tranexamic acid reduces blood loss and blood transfusion after knee arthroplasty: a prospective, randomised, double-blind study of 86 patients. J Bone Joint Surg Br 1996 78:434-440.

32. Husted H, Blønd L, Sonne-Holm S, et al: Tranexamic acid reduces blood loss and blood transfusions in primary total hip arthroplasty: a prospective randomized double-blind study in 40 patients. Acta Orthop Scand 2003, 74:665-669.

33. Ido K, Neo M, Asada Y, et al: Reduction of blood loss using tranexamic acid in total knee and hip arthroplasties. Arch Orthop Trauma Surg 2000, 120:518-520.

34. Fiebig E: Safety of the blood supply. Clin Orthop Relat Res 1998, 357:6-18.

35. Kolisek FR, Bonutti PM, Hozack WJ, et al: Clinical experience using a minimally invasive surgical approach for total knee arthroplasty: early results of a prospective randomized study compared to a standard approach. J Arthroplasty 2007, 22:8-13.

doi:10.1186/1749-799X-7-32

Cite this article as: Mutsuzaki and Ikeda: Intra-articular injection of tranexamic acid via a drain plus drain-clamping to reduce blood loss in cementless total knee arthroplasty. Journal of Orthopaedic Surgery and Research 2012 7:32

\section{Submit your next manuscript to BioMed Central and take full advantage of:}

- Convenient online submission

- Thorough peer review

- No space constraints or color figure charges

- Immediate publication on acceptance

- Inclusion in PubMed, CAS, Scopus and Google Scholar

- Research which is freely available for redistribution 